\title{
Analisa Perencanaan Pembayaran Menggunakan Sistem QR Code di Industria/ Universitas Advent Indonesia
}

\author{
Santa Frita Saragih ${ }^{1}$, Elmor Benedict Wagiu ${ }^{2}$ \\ 1,2Fakultas Teknologi Informasi, Universitas Advent Indonesia \\ e-mail: ${ }^{1}$ sanfrita18@gmail.com, 2elmor@unai.edu
}

\begin{abstract}
Abstrak
Sistem pembayaran di Industria/ Universitas Advent Indonesia saat ini menggunakan uang tunai dan pencatatan keuangan dilakukan secara manual. Oleh karena itu terdapat permasalahan yang terjadi karena pencatatan keuangan hasil penjualan masih dicatat di dalam buku dan buku itu nantinya diberikan kepada Biro Akademik Keuangan (BAK) sebagai laporan. Penelitian ini bertujuan untuk memberikan gambaran sistem pembayaran baru yaitu pembayaran elektronik menggunakan QR Code sebagai solusi dalam mengatasi masalah dari pencatatan keuangan manual dan untuk mengetahui kesiapan pengguna yaitu mahasiswa, dosen dan staff mengenai sistem pembayaran baru. Metode yang digunakan dalam pengumpulan data adalah dengan wawancara, survey dan observasi, kuesioner dan studi kepustakaan. Pemodelan yang digunakan untuk merancang sistem baru adalah UML (Unified Modeling Language) dan kuesioner untuk mengetahui kesiapan pengguna. Kesimpulan penelitian ini adalah 1) Dengan sistem ini, dapat mencegah terjadi kesalahan dalam perhitungan pendapatan karena perhitungan tidak lagi dilakukan secara manual, 2) Dengan sistem ini, lupa mencatat hasil penjualan dapat diatasi karena pencatatan dilakukan secara langsung atau realtime di dalam sistem, 3) Dengan sistem ini maka tidak perlu lagi membeli buku karena semuanya sudah tercatat di dalam sistem, 4) Pengawasan terhadap keuangan akan lebih terkontrol, 5) Pencarian dan pemeriksaan data dapat dilakukan dengan mudah dan cepat, 6) Industrial Universitas Advent Indonesia tidak perlu lagi memberikan laporan penjualan ke BAK karena laporan penjualan sudah bisa langsung diakses oleh BAK di dalam sistem, 7) Berdasarkan hasil kuesioner yang telah dikumpulkan dan diolah, rata - rata jawaban keseluruhan responden dari 10 pertanyaan adalah setuju. Dapat disimpulkan bahwa pengguna/user siap terhadap sistem pembayaran elektronik di Industrial Universitas Advent Indonesia.
\end{abstract}

Kata Kunci: QR Code, Sistem Pembayaran Elektronik, UML, BPMN

\section{The Analysis of The Payment Planning Using the QR Code System in The Industrial of Universitas Advent Indonesia}

\begin{abstract}
Currently the payment systems in the Industrial of Universitas Advent Indonesia uses cash and the financial records are done manually. There are some problems occur because of the sales financial records are still manually recorded on the book and after that the book will be given to the Academic Finance Bureau (BAK) as the prove of report. This study aims to provide an overview of the new payment system, it is electronic payments by using the QR Code as a solution to overcome the manual financial recording problems and to find out the readiness of the users, they are the students, lecturers and staffs regarding the new payment system. The method used in data collection were interview, survey and observation, questionnaire and literature studies. The modeling used in this study to design a new system that was UML (Unified Modeling Language) and a questionnaire to determine the readiness of users. The conclusions of this study were 1) With this system, it can prevent errors at the income calculation because the calculations
\end{abstract}


are no longer done manually, 2) With this system, forgetting to record sales results can be solved because the recording is done directly or realtime in the system, 3) With this system, no need to buy books to record the sales because everything is recorded in the system, 4) Financial supervision will be easily to be controlled, 5) Searching and inspection of data is easy and quick, 6) The Industrial of Universitas Advent Indonesia no need to provide sales report to BAK because the sales report can be directly accessed by BAK in the system, 7) Based on the results of the questionnaire that has been collected and processed, the overall average answer of the respondents from the 10 questions provided are agreed. It can be concluded that the user is ready for the electronic payment system in the Industrial of Universitas Advent Indonesia.

Keywords: QR Code, Electronic Payment System, UML, BPMN

\section{Pendahuluan}

Perkembangan teknologi yang semakin maju memberikan kemudahan dalam berbagai bidang dan aspek kehidupan, termasuk dalam kegiatan transaksi pembayaran. Oleh karena itu teknologi dalam kegiatan pembayaran dapat menggeser penggunaan uang tunai sebagai alat pembayaran ke bentuk pembayaran non tunai. Salah satu bentuk pembayaran non tunai adalah uang elektronik. Uang elektronik adalah alat pembayaran yang memenuhi faktor- faktor yaitu diterbitkan oleh bank atas dasar nilai uang yang disetor terlebih dahulu oleh pemegang, nilai uang yang tersimpan secara elektronik dalam suatu media seperti chip atau server dan digunakan sebagai alat pembayaran kepada penjual barang atau jasa [6].

Menurut hasil statistik Bank Indonesia, mengenai jumlah uang elektronik (Terpisah dengan pengaturan mengenai alat pembayaran dengan menggunakan kartu) yang beredar di Indonesia, pada Desember 2017 sejumlah Rp.90.003.848, pada Desember 2018 mencapai Rp.167.205.578 dan pada Februari 2019 mencapai Rp.189.222.546 [3]. Kesimpulannya adalah tahun ke tahun penggunaan uang elektronik akan terus meningkat.

Dengan adanya kemajuan teknologi, universitas disarankan untuk melakukan digitalisasi kampus. Digitalisasi ini bisa menjadi keunggulan serta daya tarik dari suatu universitas. Universitas Advent Indonesia (UNAI) adalah salah satu dari beberapa universitas di kota Bandung. Universitas ini terletak di Parongpong, Bandung Barat. Untuk menjadi universitas yang unggul dalam teknologi, diperlukan perencanaan strategis mengenai penerapan beberapa teknologi yang dapat menjadi daya tarik dari universitas tersebut. Salah satunya dalam kegiatan transaksi pembayaran melalui uang elektronik yang bisa dilakukan di industrial universitas. Industria/Universitas Advent Indonesia adalah Laundry, Fotokopi, UNAI Bakery, OMI dan UNAI Klinik.

Selama ini pembayaran di industria/ Universitas Advent Indonesia masih menggunakan uang tunai. Pencatatan transaksi manual dan pemberian uang hasil penjualan ke Biro Administrasi Keuangan (BAK) masih dalam bentuk uang tunai. Masalah yang timbul dari sistem manual ini adalah adanya kemungkinan terjadi kesalahan dalam perhitungan pendapatan di industrial Universitas Advent Indonesia, adanya kemungkinan untuk lupa mencatat hasil penjualan, pencatatan manual dengan buku butuh biaya, rentan hilang dan rusak, kurangnya pengawasan terhadap keuangan, pencarian dan pemeriksaan data menjadi sulit dan lama, serta lambatnya penyerahan uang dan laporan penjualan dari industria/ ke BAK. Penelitian ini memanfaatkan Quick Response Code (QR Code) untuk sistem pembayaran yang dapat diterapkan di industria/ Universitas Advent Indonesia.

\section{Landasan Teori}

\section{Electronic Payment (E-payment)}

Pembayaran elektronik ( $E$-Payment) adalah alat pembayaran berbentuk elektronik di mana terdapat nilai uang yang tersimpan dalam media elektronik tertentu [9]. Pengguna pembayaran elektronik terlebih 
dahulu akan menyetorkan uangnya ke penerbit untuk disimpan dan digunakan untuk bertransaksi. Ketika digunakan untuk bertransaksi, nilai uang elektronik pengguna yang tersimpan akan berkurang sebesar nilai transaksi. Jika uang elektronik yang tersimpan habis, pengguna dapat mengisinya kembali atau biasanya disebut dengan top up. Dapat disimpulkan bahwa Electronic Payment (E-payment) adalah sistem pembayaran barang atau jasa yang dilakukan menggunakan uang elektronik dan membutuhkan internet.

\section{Teknologi Quick Response Code (QR Code)}

Quick response dapat diterjemahkan menjadi respons cepat. QR Code adalah matriks dua dimensi yang dapat menyimpan banyak data di dalamnya dan dapat dibaca dengan cepat menggunakan alat pemindai. QR Code di kembangkan oleh Denso Corporate, yaitu perusahaan jepang pada tahun 1994. QR Code adalah evolusi dari Barcode. Model barcode, data hanya dapat disimpan secara horizontal sedangkan QR Code data dapat disimpan secara horizontal maupun vertikal [13].

\section{Proses Bisnis}

"Proses bisnis adalah aktivitas atau proses yang terstruktur dan saling berhubungan di dalam organisasi untuk mengelola sumber daya dalam rangka mencapai sebuah tujuan yang menciptakan nilai tambah bagi organisasi." [2]. Dari definisi di atas dapat disimpulkan bahwa proses bisnis adalah suatu kumpulan aktivitas yang berhubungan satu sama lain untuk menghasilkan keluaran produk barang atau jasa yang bernilai, dalam mencapai suatu tujuan.

\section{Business Process Model and Notation (BPMN)}

Business Process Model and Notation adalah standar untuk menggambarkan diagram alur proses bisnis dengan menggunakan notasi grafis. Tujuan dari Business Process Modeling Notation (BPMN) adalah menggambarkan suatu bisnis proses diagram dengan dasar teknik diagram alur, dirangkai untuk membuat model grafis dari urutan aktivitas-aktivitas dalam operasi bisnis dan kontrol alur yang mendefinisikan urutan kerja [7].

\section{Unified Modeling Language (UML)}

Unified Modeling Language (UML) merupakan standarisasi bahasa pemodelan dalam membangun perangkat lunak yang menggunakan teknik pemrograman berorientasi objek. UML dapat digunakan untuk maksud tertentu antara lain untuk merancang perangkat lunak, sebagai sarana komunikasi antara perangka lunak dengan proses bisnis, menjabarkan sistem secara rinci/detail untuk analisis dan mencari apa yang diperlukan sistem, dan juga mendokumentasi sistem yang ada, proses- proses serta organisasinya [8].

\section{Identifikasi Masalah}

Identifikasi masalah dalam proses bisnis berdasarkan hasil dari wawancara dan survey secara langsung. Berdasarkan hasil analisa terhadap proses bisnis yang sedang berjalan saat ini, kendala yang di dapatkan adalah sebagai berikut:

1. Adanya kemungkinan terjadi kesalahan dalam perhitungan pendapatan di industria/ Universitas Advent Indonesia.

2. Adanya kemungkinan untuk lupa mencatat hasil penjualan.

3. Pencatatan manual dengan buku butuh biaya, rentan hilang dan rusak.

4. Kurangnya pengawasan terhadap keuangan.

5. Pencarian dan pemeriksaan data menjadi sulit dan lama.

6. Lambatnya penyerahan uang dan laporan penjualan dari industria/ke BAK.

7. Bagaimana mengetahui kesiapan pengguna terhadap sistem pembayaran elektronik. 


\section{Ruang Lingkup dan Batasan Penelitian}

Agar penulisan ini dapat terarah tidak keluar dari pokok permasalahan yang dirumuskan, maka ruang lingkup pembahasan dibatasi sebagai berikut:

1. Tidak membahas keuntungan dalam segi uang yang didapatkan Universitas Advent Indonesia mengenai penerapan sistem pembayaran elektronik.

2. Penelitian ini tidak membahas komponen - komponen dalam pembuatan sistem pembayaran QR Code di android untuk pengguna dan juga web untuk BAK (admin).

3. Tidak membahas strategi yang dapat dilakukan agar semua pembeli di industria/Universitas Advent Indonesia menggunakan sistem pembayaran elektronik ini.

\section{Maksud dan Tujuan Penelitian}

Maksud dari penelitian ini adalah untuk mengusulkan penggunaan sistem QR Code sebagai metode pembayaran elektronik di industria/Universitas Advent Indonesia.

Tujuan dari penelitian ini adalah agar mendapatkan gambaran sistem pembayaran elektronik baru yaitu QR Code sebagai solusi dalam mengatasi masalah dari pencatatan keuangan manual dan mengetahui kesiapan pengguna yaitu mahasiswa, dosen dan staff mengenai sistem pembayaran elektronik.

\section{Metodologi Penelitian}

Metode penelitian yang digunakan sebagai berikut:

1. Survey Lapangan (field research)

Memperoleh data untuk analisa dengan cara:

1.1 Wawancara langsung dengan pihak - pihak yang terkait dalam mengelola industrial Universitas Advent Indonesia.

1.2 Melakukan pengamatan dan observasi mengenai bagaimana jika disarankan sistem baru dalam sistem pembayaran di industria/ Universitas Advent Indonesia.

1.3 Membuat daftar pertanyaan atau kuesioner yang ditujukan kepada mahasiswa, dosen dan staff untuk mengetahui kesiapan mereka dalam menerima sistem pembayaran elektronik.

2. Studi Kepustakaan (library research)

Melakukan pengumpulan landasan teori dan referensi melalui membaca buku-buku referensi yang terkait dengan penelitian ini dan dari internet.

\section{Hasil dan Pembahasan}

Analisa proses bisnis di industria/Universitas Advent Indonesia yaitu Departemen Laundry, Fotokopi, UNAI Bakery, OMI, dan Klinik UNAI adalah sebagai berikut :

\section{Proses Bisnis Pembayaran di Laundry}

Berikut adalah tahapan melakukan transaksi di Laundry. Pertama, pembeli (mahasiswa, dosen dan staff) membawa pakaian kotor ke laundry Universitas Advent Indonesia. Kedua, pihak laundry menerima pakaian kotor. Ketiga, setelah menerima pakaian kotor pihak laundryakan menimbang berat pakaian kotor tersebut. Keempat, kemudian mencatat nama pembeli, berat, harga, tanggal terima dan tanggal selesai laundry di bon. Pihak laundry menyerahkan bon ke pembeli. Kelima, lalu pihak laundry akan melakukan proses laundry dan dikemas. Keenam, pembeli mengambil pakaiannya dengan menunjukkan bon dan bayar menggunakan uang tunai kepada pihak laundry. Pihak laundry lalu menyerahkan pakaian laundry ke pembeli. Ilustrasi mengenai Proses Bisnis dapat dilihat pada Gambar 1. 


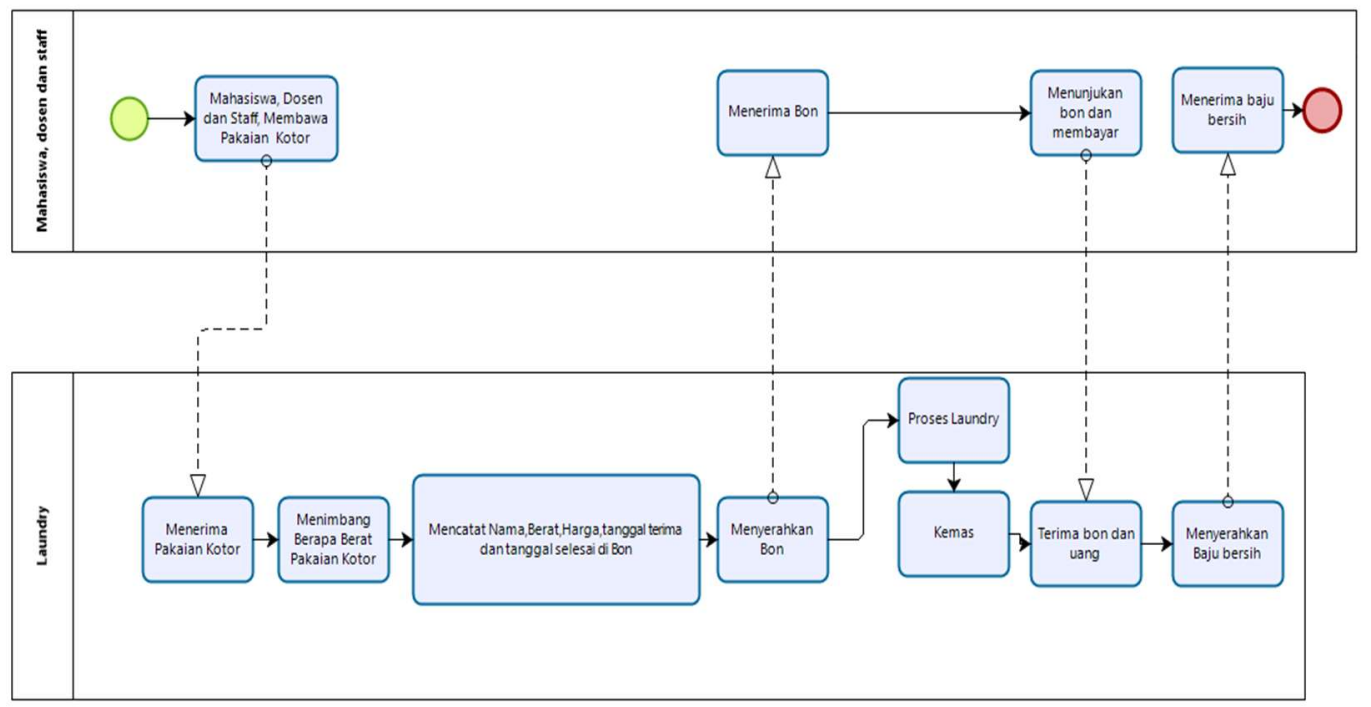

Gambar 1 Proses Bisnis Pembayaran di Laundry

\section{Proses Bisnis Pembayaran di Fotokopi}

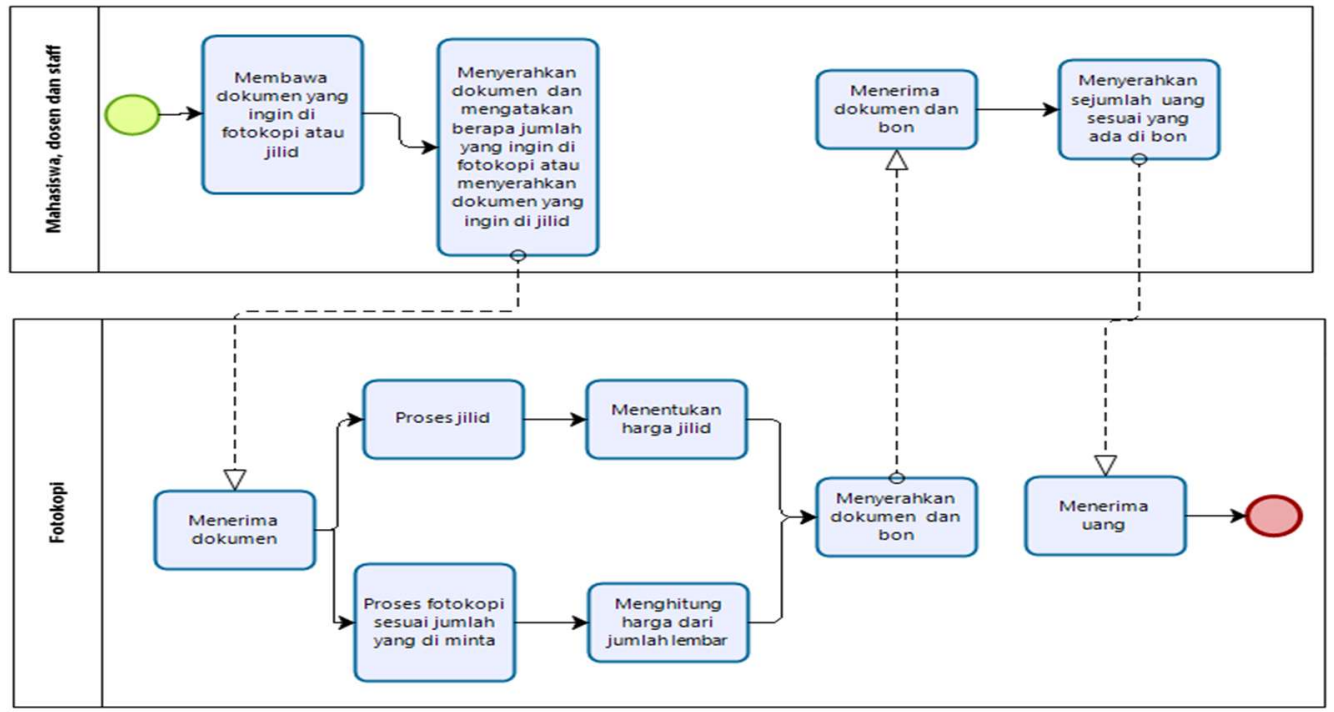

Gambar 2 Proses Bisnis Pembayaran di Fotokopi

Penjelasan dari Gambar 2 di atas:

Pertama, pembeli (mahasiswa, dosen dan staff) menyerahkan dokumen dan memberitahu jumlah dokumen yang ingin di fotokopi atau jilid kepada pihak fotokopi. Kedua, lalu pihak fotokopi akan melakukan proses fotokopi atau jilid sesuai permintaan pembeli. Ketiga, setelah selesai, pihak fotokopi menghitung harga fotokopi atau jilid dan menyerahkan dokumen kepada pembeli. Keempat, pembeli membayar sesuai harga yang disampaikan pihak fotokopi. 


\section{Proses Bisnis Pembelian dan Pembayaran di UNAI Bakery}

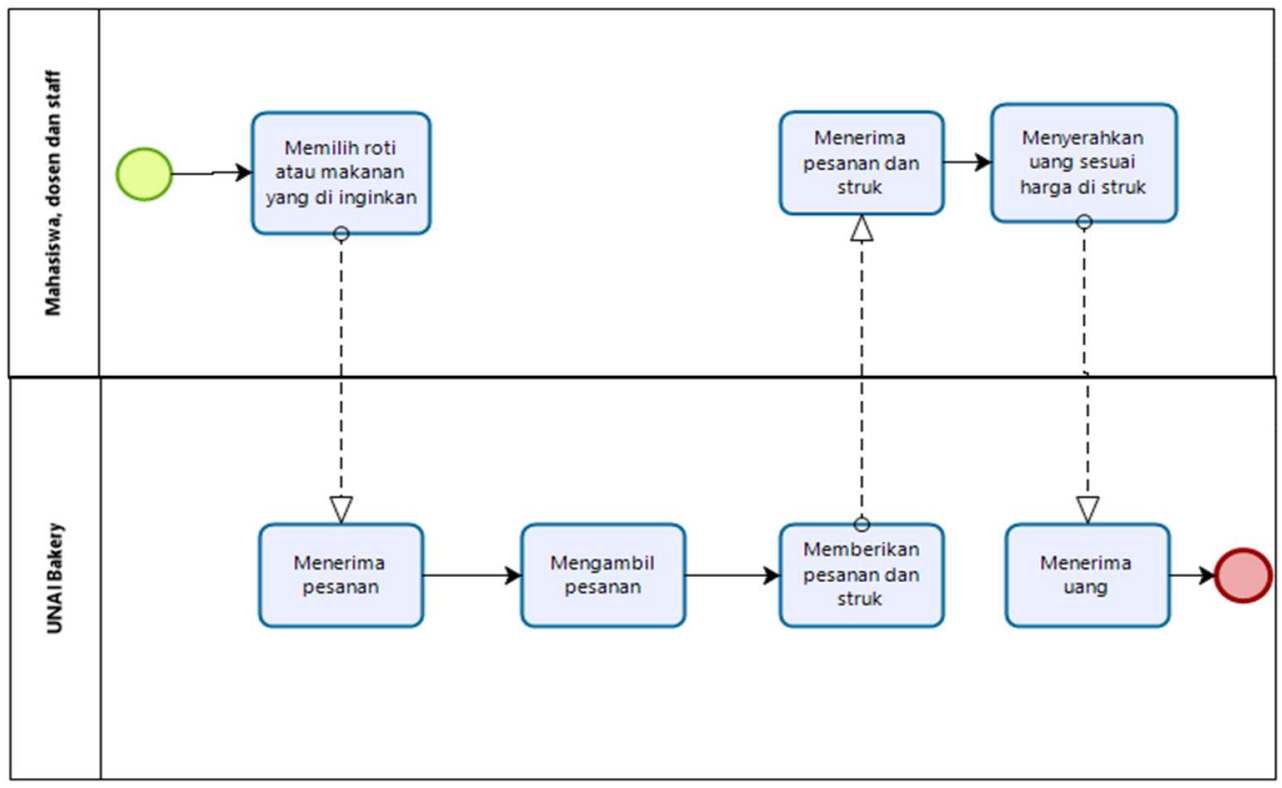

Gambar 3 Proses Bisnis Pembelian dan Pembayaran UNAI Bakery

Penjelasan dari Gambar 3 di atas:

Pertama, pembeli (mahasiswa, dosen dan staff) memilih roti yang ingin di beli. Kedua, pihak UNAI Bakery akan mengambil pesanan dan menghitung harga pembelian roti. Lalu menyerahkan pesanan dan struk ke pembeli. Ketiga, pembeli akan membayar sesuai harga yang tertera di struk kepada pihak UNAI Bakery.

\section{Proses Bisnis Pembelian dan Pembayaran di OMI}

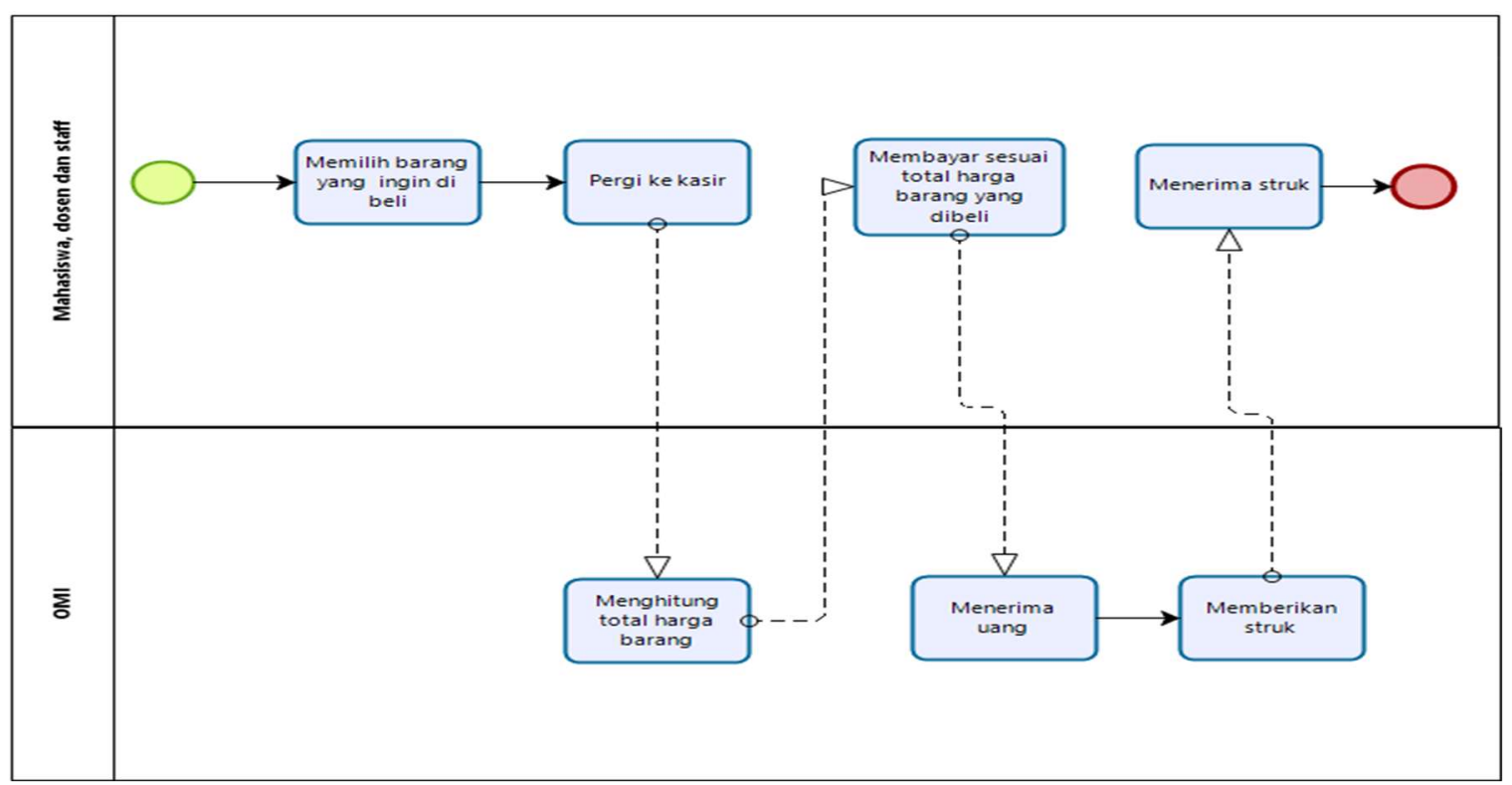

Gambar 4 Proses Bisnis Pembelian dan Pembayaran di OMI 
Penjelasan dari Gambar 4 adalah sebagai berikut:

Pertama, pembeli (mahasiswa, dosen dan staff) memilih barang yang ingin dibeli lalu pergi ke kasir dan menyerahkan barang yang ingin dibayar. Kedua, OMI akan menghitung total harga barang tersebut dan pembeli akan membayar sesuai total harga barang yang dibeli. Ketiga, OMI akan menerima uang dan memberikan struk kepada pembeli.

Proses Bisnis Pembayaran Rawat Inap dan Rawat Jalan di UNAI Klinik

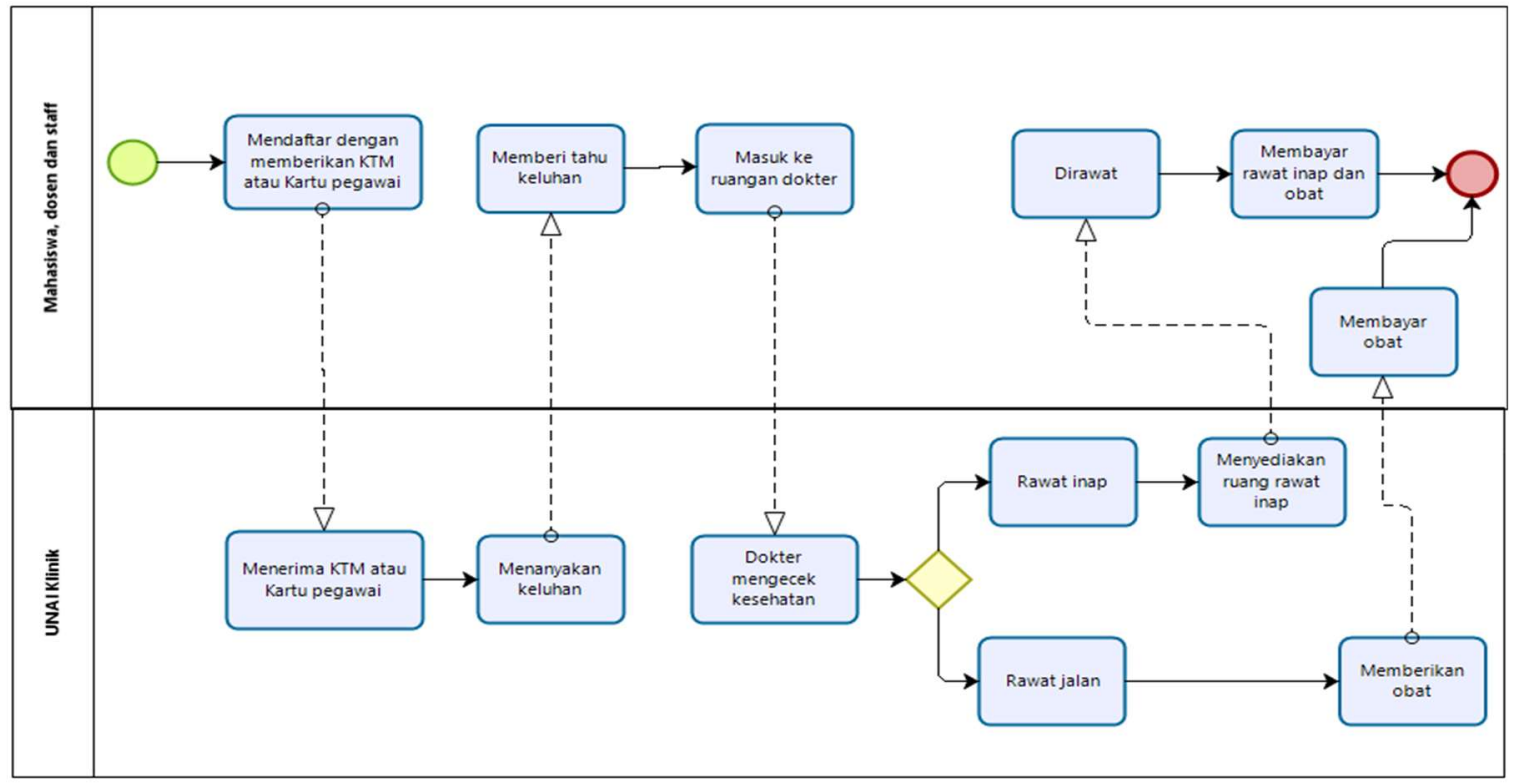

Gambar 5 Proses Bisnis Pembayaran Rawat Inap dan Rawat Jalan di UNAI Klinik

Penjelasan dari Gambar 5 di atas:

Pertama, Pasien (mahasiswa, dosen dan staff) akan mendaftar dengan memberikan KTM atau kartu pegawai. Kedua, UNAI Klinik akan menanyakan keluhan pasien. Ketiga, pasien akan masuk ke ruangan dokter lalu dokter akan menentukan apakah harus dirawat inap atau rawat jalan. Jika harus rawat inap, maka UNAI Klinik akan menyediakan ruang rawat inap, lalu pasien akan dirawat kemudian akan membayar rawat inap dan obat. Jika pasien rawat jalan, maka UNAI Klinik akan langsung memberikan obat dan pasien akan membayar obat.

\section{Sistem Pembayaran Elektronik}

Dari analisa yang sudah dilakukan terhadap proses bisnis yang sedang berlangsung di Universitas Advent Indonesia, maka dapat diidentifikasi beberapa fitur yang dapat digunakan ke dalam sistem yang baru. Adapun fitur tersebut adalah sebagai berikut:

1. Pembayaran di industria/Universitas Advent Indonesia menggunakan sistem pembayaran non tunai (cashless).

2. Semua pembayaran menggunakan aplikasi.

3. Semua riwayat transaksi pembayaran langsung atau realtime masuk ke BAK.

4. Riwayat pembelian tercatat di aplikasi user.

5. Riwayat penjualan tercatat di aplikasi penjual.

6. Semua data-data penjualan dan pembelian tercatat di sistem BAK. 
7. Semua transaksi yang dilakukan di industrial Universitas Advent Indonesia akan langsung tercatat dalam sistem BAK secara realtime.

8. Pengguna aplikasi Top Up saldo di BAK.

9. Sistem mampu menghitung rekapitulasi pendapatan di industria/ Universitas Advent Indonesia.

\section{Gambaran Sistem Pembayaran Elektronik}

\section{Sistem untuk BAK}

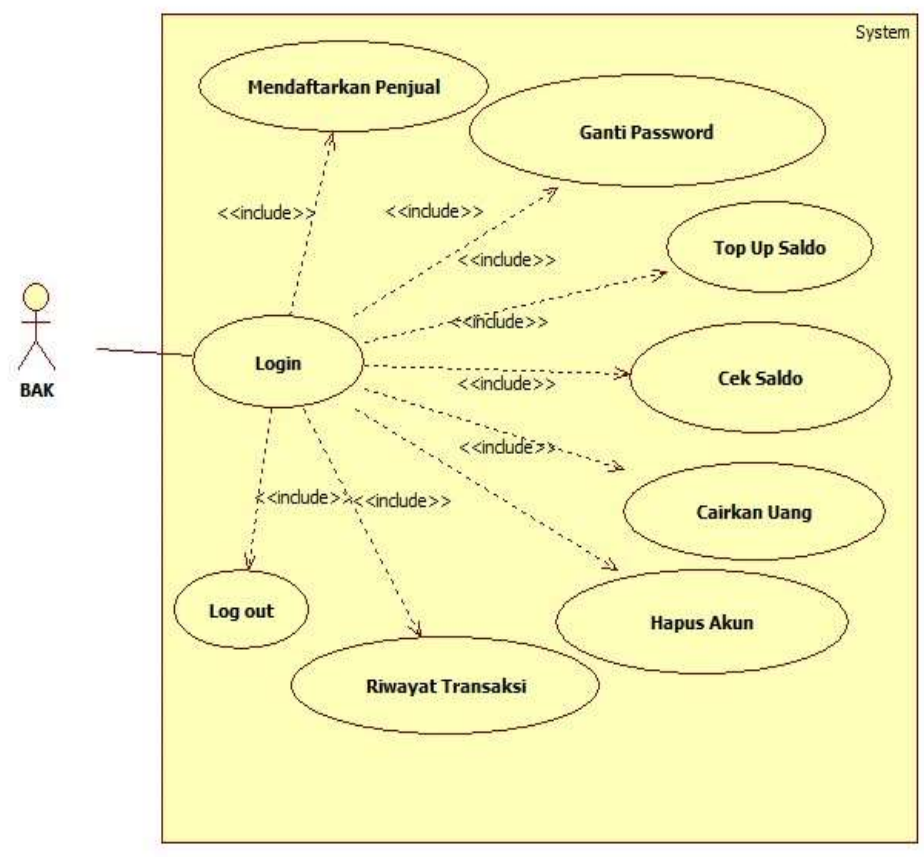

Gambar 6 Usecase BAK

Hal yang pertama di lakukan oleh BAK adalah login dengan menggunakan username dan password. Yang bisa dilakukan BAK adalah 1) Mendaftarkan penjual. BAK mendaftarkan penjual di Industrial Universitas Advent Indonesia secara khusus. Penjual akan mendapatkan username dan password untuk mengakses aplikasi penjualan. 2) Ganti password. Jika mahasiswa, dosen, dan staff lupa password atau kehilangan smartphone mereka, user dapat mengubah passworchya di BAK. 3) Top Up. Pengisian saldo hanya bisa di lakukan oleh BAK. 4) Cek Saldo. BAK bisa melihat semua saldo mahasiswa, dosen, staff maupun saldo industria/Universitas Advent Indonesia. 5) Cairkan uang. Menu cairkan uang ini dikhususkan untuk industrial Universitas Advent Indonesia. Agar saat BAK mencairkan uang dari akun industrial, pengurangan saldo akan langsung berkurang sesuai dengan jumlah uang yang ingin di cairkan. 6) Hapus akun. BAK dapat menghapus mahasiswa, dosen, dan staff. 7) Riwayat Transaksi Penjualan. BAK dapat melihat laporan riwayat transaksi penjualan industria/ Universitas Advent Indonesia secara langsung atau realtime. 


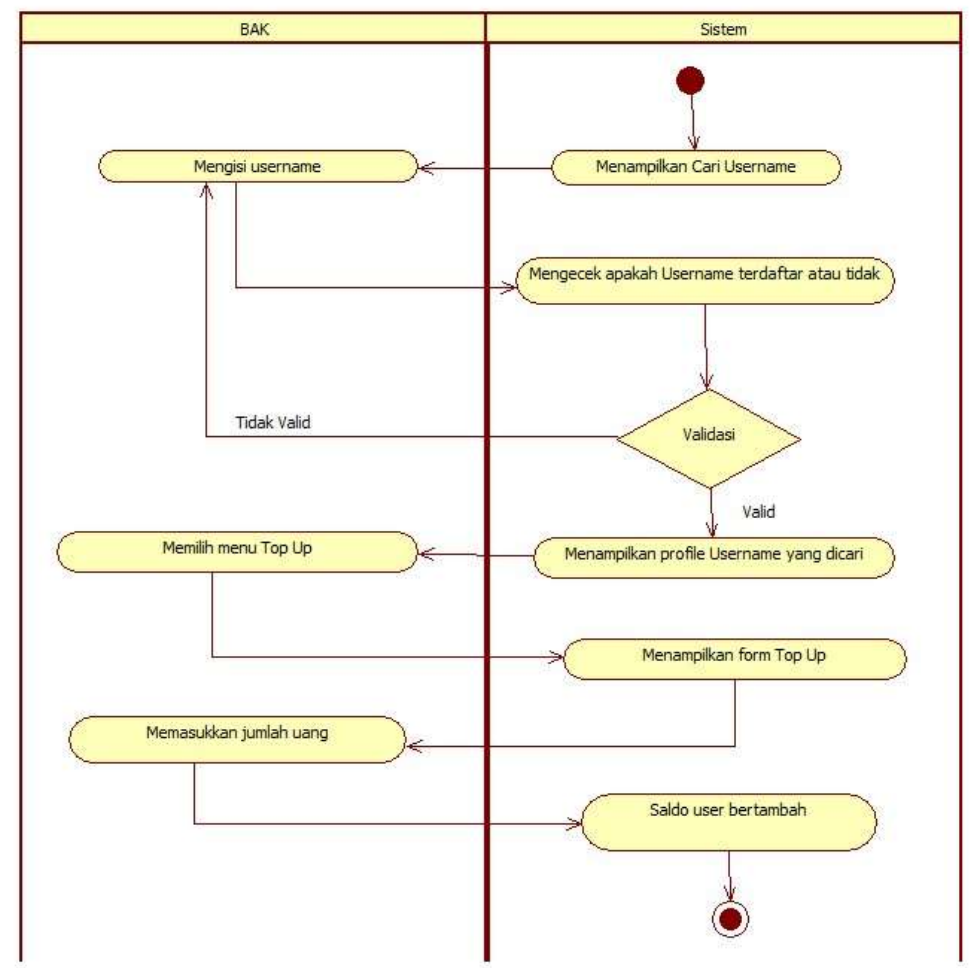

Gambar 7 Activity Diagram BAK Melakukan Top Up

Penjelasan dari Activity Diagram di atas adalah pertama, sistem menampilkan menu Cari Username. Kedua, BAK mengisi nama username yang ingin dicari. Ketiga, sistem memeriksa apakah Username terdaftar atau tidak. Keempat, sistem melakukan validasi, jika username terdaftar, sistem akan menampilkan profile Username yang dicari. Jika username tidak ditemukan, maka BAK harus mengisi ulang username. Kelima, saat sistem sudah menampilkan profile username yang sudah dicari maka BAK akan memilih menu Top Up. Keenam, sistem menampilkan form Top Up. Ketujuh, BAK memasukkan jumlah uang/saldo. Kedelapan, sistem menambahkan jumlah saldo user.

\section{Sistem untuk mahasiswa, dosen dan staff}

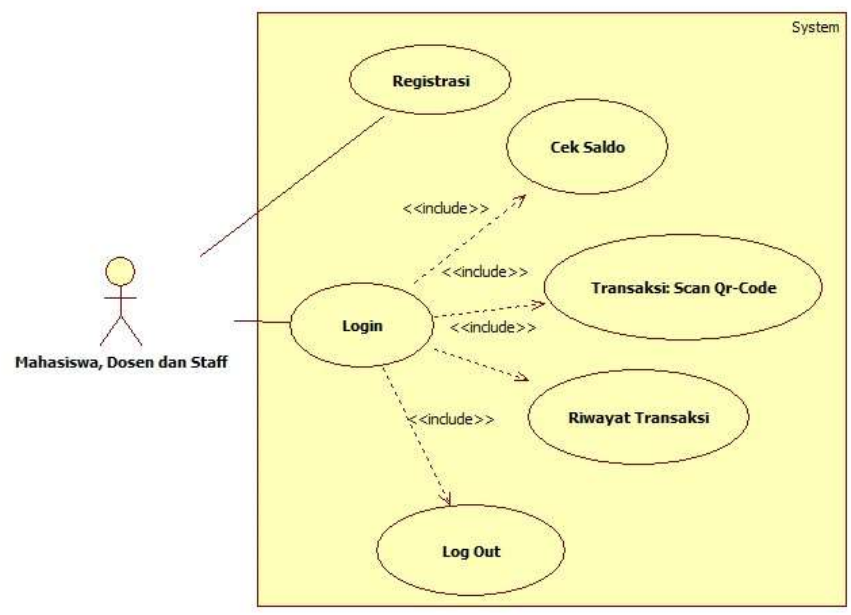

Gambar 8 Usecase Diagram Mahasiswa, Dosen dan Staff 
Hal yang pertama kali dilakukan oleh mahasiswa, dosen dan staff adalah registrasi kemudian login. Yang bisa di lakukan oleh mahasiswa, dosen dan staff adalah 1) Melihat saldo yang ada dalam akun. 2) Transaksi scan QR Code. Pembayaran dilakukan dengan cara scan QR Code yang tersedia di masing-masing industrial Universitas Advent Indonesia, lalu mengisi jumlah uang yang ingin dibayarkan. 3) Riwayat transaksi. Dapat melihat riwayat transaksi pembayarannya secara langsung. 4) Log out.

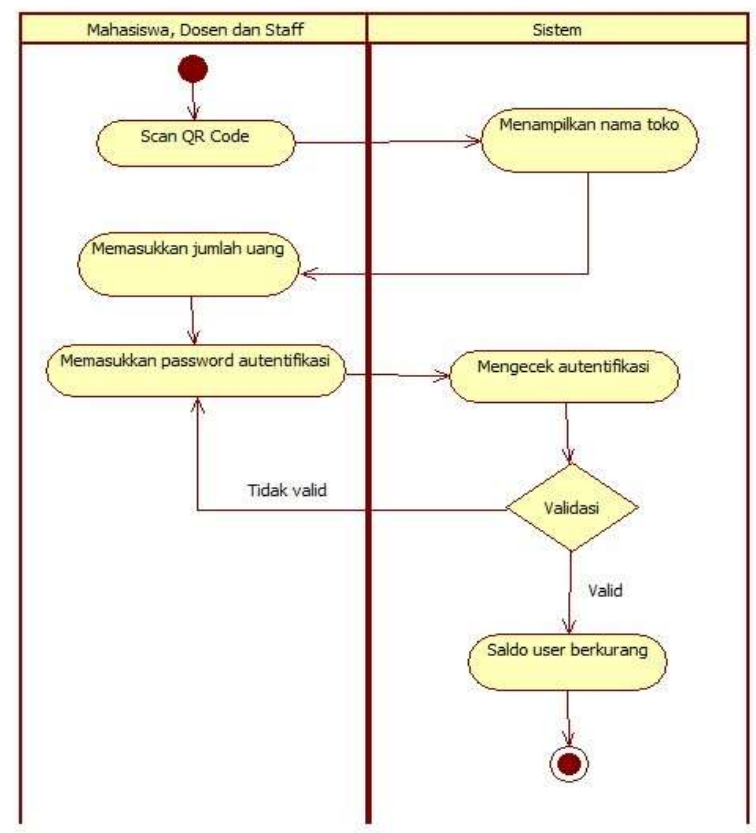

Gambar 9 Activity Diagram User Scan QR Code

Penjelasan Activity Diagram di atas adalah pertama mahasiswa, dosen dan staff melakukan Scan QR Code. Kedua, sistem akan menampilkan nama toko. Ketiga, mahasiswa, dosen dan staff memasukkan jumlah uang. Keempat, mahasiswa, dosen dan staff memasukkan password autentifikasi. Kelima, sistem akan memeriksa autentifikasi. Keenam, sistem melakukan validasi. Jika password autentifikasi benar maka saldo mahasiswa, dosen dan staffakan berkurang sesuai dengan jumlah pembayaran. Jika password salah, maka user harus mengisi ulang password autentifikasi.

\section{Sistem Penjual di Industria/ Universitas Advent Indonesia}

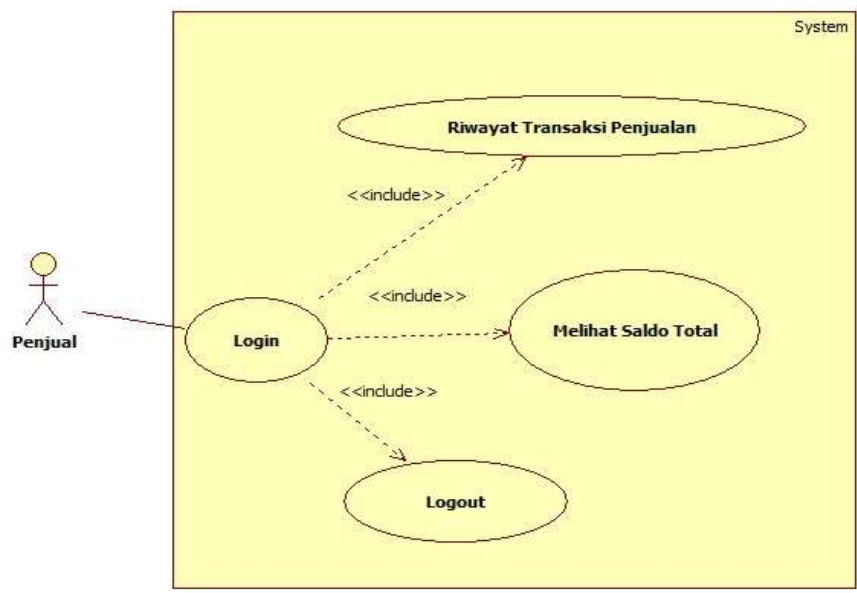

Gambar 10 Usecase Penjual 
Hal yang pertama kali penjual lakukan adalah login. Yang bisa dilakukan penjual adalah melihat saldo total dan melihat riwayat transaksi penjualan.

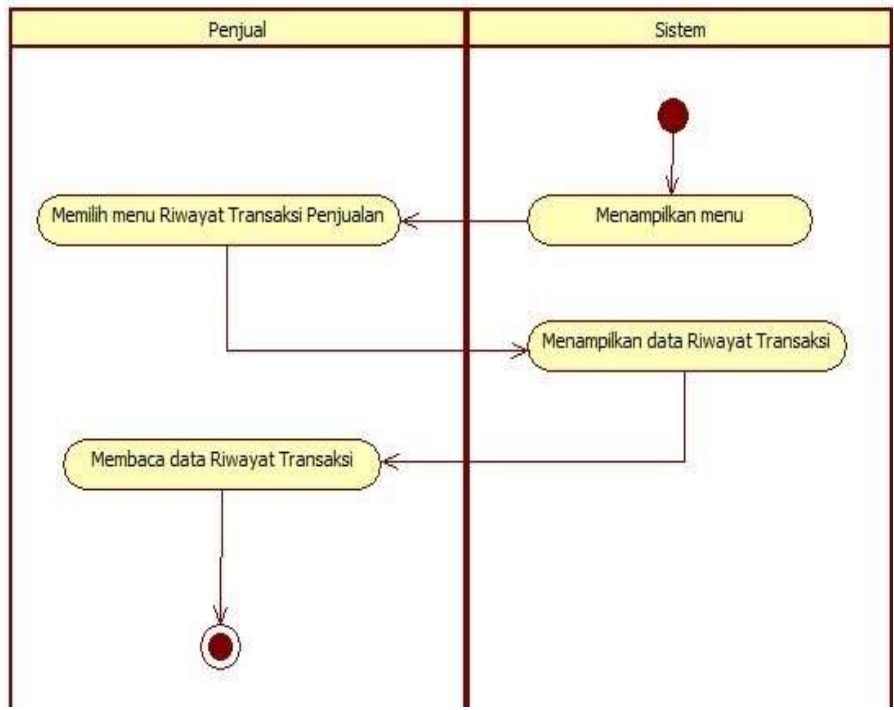

Gambar 11 Activity Diagram Penjual Melihat Riwayat Transaksi Penjualan

Penjelasan Activity Diagram di atas adalah pertama, sistem menampilkan menu. Kedua, penjual memilih menu Riwayat Transaksi Penjualan. Ketiga, sistem menampilkan data Riwayat Transaksi.

\section{Pengambilan Sampel}

"Populasi adalah wilayah generalisasi yang terdiri atas obyek atau subyek yang memiliki kuantitas dan karakteristik tertentu yang ditetapkan oleh peneliti untuk dipelajari dan kemudian menghasilkan kesimpulannya." [11]. Populasi yang akan diteliti adalah Universitas Advent Indonesia yang terdiri dari mahasiswa, dosen dan staff.

Sampel merupakan sebagian kecil dari anggota populasi yang menurut prosedur tertentu dapat diambil untuk mewakili populasi tersebut [11]. Menurut Roscoe dalam Sugiyono mengenai menentukan ukuran sampel yaitu:

1. Ukuran sampel yang lebih dari 30 dan kurang dari 500 ialah tepat untuk kebanyakan penelitian.

2. Jika sampel dipecah ke dalam sub-sampel (pria/wanita, junior/senior dan sebagainya), ukuran sampel minimum 30 untuk tiap kategori adalah tepat. [12]

Pengambilan sampel diambil masing-masing sebanyak 30 dari beberapa kategori yaitu dosen, staff dan mahasiswa dari 6 fakultas yaitu filsafat, keguruan dan ilmu pendidikan, ekonomi, ilmu keperawatan, matematika \& ilmu pengetahuan alam, dan teknologi informasi. Total jumlah sampel yang diambil peneliti adalah 240 sampel dan penulis menggunakan tingkat kesalahan sebesar $5 \%$ sehingga kebenaran/ketelitian data sampelnya sebesar $95 \%$.

\section{Analisa Menggunakan Kuesioner}

"Angket atau kuesioner merupakan cara pengumpulan data dengan memberikan pertanyaan secara tertulis yang akan dijawab oleh responden, agar peneliti memperoleh data lapangan/empiris untuk memecahkan masalah penelitian dan menguji hipotesis yang telah ditetapkan." [4] 
Kuesioner yang diberikan kepada responden menggunakan Skala Likert. Skala Likert merupakan media pengungkapan persepsi dan pendapat seseorang terhadap suatu pernyataan yang tertulis di dalam angket/kuesioner, yaitu seperti pada tabel berikut :

Tabel 1 Skala Likert

\begin{tabular}{|l|l|}
\hline Sangat Tidak Setuju & 1 \\
\hline Tidak Setuju & 2 \\
\hline Kurang Setuju & 3 \\
\hline Setuju & 4 \\
\hline Sangat Setuju & 5 \\
\hline
\end{tabular}

\section{Uji Validitas}

Validitas adalah untuk menunjukkan sejauh mana ketepatan suatu alat ukur, apakah tes tersebut benar - benar mengukur apa yang seharusnya diukur dan kesimpulan valid / invalid diambil berdasarkan skor [1].

Untuk mengetahui apakah pertanyaan valid atau tidak, pertanyaan yang ada di dalam kuesioner diuji validitas dan reliabilitas menggunakan Statistical Package Social Science (SPSS) dengan mengambil 50 sampel. Maka diperoleh hasil uji validasi dalam penelitian sebagai berikut :

Tabel 2 Hasil Uji Validitas

\begin{tabular}{|c|c|c|c|}
\hline No Soal & R hitung & R tabel 5\% (50) & Keterangan \\
\hline 1 & 0.697 & 0,279 & Valid \\
\hline 2 & 0.617 & 0,279 & Valid \\
\hline 3 & 0.535 & 0,279 & Valid \\
\hline 4 & 0.635 & 0,279 & Valid \\
\hline 5 & 0.708 & 0,279 & Valid \\
\hline 6 & 0.638 & 0,279 & Valid \\
\hline 7 & 0.589 & 0,279 & Valid \\
\hline 8 & 0.367 & 0,279 & Valid \\
\hline 9 & 0.545 & 0,279 & Valid \\
\hline 10 & 0.614 & 0,279 & Valid \\
\hline
\end{tabular}

Sumber : Data primer yang telah diolah

Pada taraf tingkat kesalahan sebesar 5\%, rtabel dari 50 sampel adalah sebesar $=0,279$. Tabel 2 di atas menunjukkan bahwa R Hitung lebih besar dari R Tabel ( $\left.r_{\text {hitung }}>r_{\text {tabel }}\right)$. Sehingga dapat disimpulkan bahwa semua data (angket) adalah valid.

\section{Uji Reliabilitas}

Reliabilitas merupakan ukuran yang menunjukkan sejauh mana hasil pengukuran akan tetap konsisten bila diukur beberapa kali dengan alat ukur yang sama [10].

Perhitungan : Cronbach's Alpha $=0,789$

\section{Reliability Statistics}

\begin{tabular}{|c|r|}
\hline $\begin{array}{c}\text { Cronbach's } \\
\text { Alpha }\end{array}$ & N of ltems \\
\hline .789 & 10 \\
\hline
\end{tabular}


Tabel 3 Koefisien Reliabilitas menurut Kline dalam Riadi [5]

\begin{tabular}{|c|l|}
\hline Cronbach's Alpha & \multicolumn{1}{c|}{ Internal Consistency ${ }^{*}$ ) } \\
\hline$\alpha \geq 0.9$ & Excellent (High-Stakes Testing) \\
\hline $0.7 \leq \alpha<0.9$ & Good (Low-Stakes Testing) \\
\hline $0.6 \leq \alpha<0.7$ & Acceptable \\
\hline $0.5 \leq \alpha<0.6$ & Poor \\
\hline$\alpha<0.5$ & Unacceptable \\
\hline
\end{tabular}

Hasil perhitungan reliabilitas Cronbach's Alpha adalah 0.789 , di mana 0.789 dalam tabel koefisien reliabilitas adalah good sehingga dapat disimpulkan bahwa data (angket) reliabel atau konsisten dengan baik.

\section{Hasil Perhitungan}

Berdasarkan hasil kuesioner yang sudah diberikan kepada 240 sampel. Maka hasil kuesioner setelah dihitung rata - ratanya adalah sebagai berikut:

Tabel 4 Hasil olah kuesioner

\begin{tabular}{|l|c|}
\hline \multicolumn{1}{|c|}{ Hasil Rata - Rata Jawaban Kuesioner } & \multicolumn{1}{|c|}{ Rata - rata } \\
\hline Pertanyaan & 4.12 \\
\hline Pertanyaan 1: Pembayaran elektronik mudah dipahami & 4.31 \\
\hline Pertanyaan 2: Pembayaran elektronik mudah digunakan & 4.13 \\
\hline Pertanyaan 3: Saya pernah menggunakan pembayaran elektronik & 4.46 \\
\hline $\begin{array}{l}\text { Pertanyaan 4: Saya cukup memiliki kemampuan dalam menggunakan pembayaran } \\
\text { elektronik }\end{array}$ & 4.17 \\
\hline $\begin{array}{l}\text { Pertanyaan 5: Pembayaran elektronik membuat transaksi pembayaran menjadi } \\
\text { lebih cepat dan mudah }\end{array}$ & 4.22 \\
\hline $\begin{array}{l}\text { Pertanyaan 6: Penerapan pembayaran elektronik di kawasan industria/UNAI adalah } \\
\text { ide yang tepat }\end{array}$ & 4.52 \\
\hline $\begin{array}{l}\text { Pertanyaan 7: Saya berniat untuk menggunakan pembayaran elektronik jika itu } \\
\text { diterapkan di UNAI }\end{array}$ & 3.93 \\
\hline Pertanyaan 8: Saya tidak suka lama untuk mengantri pembayaran & 4.29 \\
\hline $\begin{array}{l}\text { Pertanyaan 9: Saya lebih sering lupa untuk membawa dompet daripada membawa } \\
\text { smartphone }\end{array}$ & \\
\hline $\begin{array}{l}\text { Pertanyaan 10: Menurut saya pembayaran melalui smartphone akan lebih efektif } \\
\text { dan praktis }\end{array}$ & \\
\hline
\end{tabular}

Penjelasan dari Tabel 4 di atas:

1. Pertanyaan nomor 1 memiliki rata - rata jawaban kuesioner yaitu 4.12, jika dibulatkan menjadi 4 . Di mana dalam tabel Skala Likert, 4 berarti setuju. Dapat disimpulkan bahwa responden setuju bahwa pembayaran elektronik mudah untuk dipahami.

2. Pertanyaan nomor 2 memiliki rata - rata jawaban kuesioner yaitu 4.31, jika dibulatkan menjadi 4. Di mana dalam tabel Skala Likert, 4 berarti setuju. Dapat disimpulkan bahwa responden setuju bahwa pembayaran elektronik mudah digunakan.

3. Pertanyaan nomor 3 memiliki rata - rata jawaban kuesioner yaitu 4.29, jika dibulatkan menjadi 4 . Di mana dalam tabel Skala Likert, 4 berarti setuju. Dapat disimpulkan bahwa responden setuju bahwa mereka pernah menggunakan pembayaran elektronik.

4. Pertanyaan nomor 4 memiliki rata - rata jawaban kuesioner yaitu 4.13, jika dibulatkan menjadi 4 . Di mana dalam tabel Skala Likert, 4 berarti setuju. Dapat disimpulkan bahwa responden setuju bahwa mereka memiliki cukup kemampuan dalam menggunakan pembayaran elektronik. 
5. Pertanyaan nomor 5 memiliki rata - rata jawaban kuesioner yaitu 4.46, jika dibulatkan menjadi 4 . Di mana dalam tabel Skala Likert, 4 berarti setuju. Dapat disimpulkan bahwa responden setuju bahwa pembayaran elektronik membuat transaksi pembayaran menjadi lebih cepat dan mudah.

6. Pertanyaan nomor 6 memiliki rata - rata jawaban kuesioner yaitu 4.17, jika dibulatkan menjadi 4 . Di mana dalam tabel Skala Likert, 4 berarti setuju. Dapat disimpulkan bahwa responden setuju bahwa penerapan pembayaran elektronik di kawasan industria/ UNAI adalah ide yang tepat.

7. Pertanyaan nomor 7 memiliki rata - rata jawaban kuesioner yaitu 4.22, jika dibulatkan menjadi 4. Di mana dalam tabel Skala Likert, 4 berarti setuju. Dapat disimpulkan bahwa responden setuju untuk ikut menggunakan pembayaran elektronik jika diterapkan di industria/UNAI.

8. Pertanyaan nomor 8 memiliki rata - rata jawaban kuesioner yaitu 4.52, jika dibulatkan menjadi 5 . Di mana dalam tabel Skala Likert, 5 berarti sangat setuju. Dapat disimpulkan bahwa responden sangat setuju bahwa mereka tidak suka lama untuk mengantri pembayaran.

9. Pertanyaan nomor 9 memiliki rata - rata jawaban kuesioner yaitu 3.93, jika dibulatkan menjadi 4. Di mana dalam tabel Skala Likert, 4 berarti setuju. Dapat disimpulkan bahwa responden setuju bahwa mereka sering lupa untuk membawa dompet daripada membawa smartphone

10. Pertanyaan nomor 10 memiliki rata - rata jawaban kuesioner yaitu 4.29 , jika dibulatkan menjadi 4. Di mana dalam tabel Skala Likert, 4 berarti setuju. Dapat disimpulkan bahwa responden setuju bahwa pembayaran melalui smartphone akan lebih efektif dan praktis.

\section{Kesimpulan}

1. Dengan sistem ini, dapat mencegah terjadi kesalahan dalam perhitungan pendapatan karena perhitungan tidak lagi dilakukan secara manual.

2. Dengan sistem ini, lupa mencatat hasil penjualan dapat diatasi karena pencatatan dilakukan secara langsung atau realtime di dalam sistem.

3. Dengan sistem ini maka tidak perlu lagi membeli buku karena semuanya sudah tercatat di dalam sistem.

4. Pengawasan terhadap keuangan akan lebih terkontrol.

5. Pencarian dan pemeriksaan data dapat dilakukan dengan mudah dan cepat.

6. Industria/ Universitas Advent Indonesia tidak perlu lagi memberikan laporan penjualan ke BAK karena laporan penjualan sudah bisa langsung diakses oleh BAK di dalam sistem.

7. Berdasarkan hasil kuesioner yang telah dikumpulkan dan diolah, rata - rata jawaban keseluruhan responden dari 10 pertanyaan adalah setuju. Dapat disimpulkan bahwa pengguna/ user siap terhadap sistem pembayaran elektronik di Industria/ Universitas Advent Indonesia.

\section{Saran}

Sistem ini akan lebih lengkap jika ditambahkan fitur transfer saldo. Fitur ini memungkinkan sesama pengguna dapat saling transfer saldo sehingga jika sewaktu - waktu pengguna dalam situasi yang darurat dikarenakan saldo habis, pengguna tidak perlu ke BAK untuk Top Up.

\section{Referensi}

[1] A. S. Hamdi and E. Bahruddin, Metode Penelitian Kuantitatif Aplikasi Dalam Pendidikan, Yogyakarta: Deepublish, 2014.

[2] A. T. Soemahadiwidjojo, Mudah Menyusun Standard Operating Procedure (SOP), Jakarta: Penebar Plus (Penebar Swadaya Grup), 2014. 
[3] Bank Indonesia, "Statistik Sistem Pembayaran," [Online]. Available: https://www.bi.go.id/id/statistik/sistem-pembayaran/uangelektronik/contents/jumlah\%20uang\%20elektronik.aspx. [Accessed 1 April 2019].

[4] E. Leonardo and F. Andreani, "Pengaruh Pemberian Kompensasi Terhadap Karyawan Pada PT. Kopanitia," Agora, vol. 3, no. 2, pp. 28-31, 2015.

[5] E. Riadi, Statistika Penelitian (Analisis Manual dan IBM SPSS), Yogyakarta: ANDI OFFSET, 2016.

[6] Ikatan Bankir Indonesia, Mengelola Kualitas Layanan Perbankan, Jakarta Pusat: PT. Gramedia Pustaka Utama, 2014.

[7] M. A. Ramdhani, "Pemodelan Proses Bisnis Sistem Akademik Menggunakan Pendekatan Business Process Modelling Notation (BPMN) (Studi Kasus Institusi Perguruan Tinggi XYZ)," Jurnal Informasi, vol. 7, no. 2, pp. 83-93, 2015.

[8] M. Muslihudin and Oktafianto, Analisis dan Perancangan Sistem Informasi Menggunakan Model Terstruktur dan UML, Yogyakarta: CV ANDI OFFSET, 2016.

[9] M. Radiansyah, "Analisis Persepsi Masyarakat Muslim Terhadap Penggunaan Alat Pembayaran Non Tunai Di Kota Medan," Universitas Islam Negeri Sumatera Utara, Medan, 2016.

[10] S. Janti, "Analisis Validitas dan Reliabilitas Dengan Skala LIKERT Terhadap Pengembangan SI/TI Dalam Penentuan Pengambilan Keputusan Penerapan Strategic Planning Pada Industri Garmen," in Prosiding Seminar Nasional Aplikasi Sains \& Teknologi (SNAST), Yogyakarta, 2014.

[11] S. Sitoyo and M. A. Sodik, Dasar Metodologi Penelitian, Yogyakarta: Literasi Media Publishing, 2015.

[12] Sugiyono, Metode Penelitian Kombinasi (Mixed Methods), Bandung: Alfabeta, 2012.

[13] Q. Aini, U. Rahardja and A. Fatilah, "Penerapan QR Code Sebagai Media Pelayanan Untuk Absensi Pada Website Berbasis PHP Native," Jurnal Ilmiah SISFOTENIKA, vol. 8, no. 1, pp. 47-56, 2018. 